\title{
Mammalian community structure in lowland, tropical Peru, as determined by removal trapping
}

\author{
NEAL WOODMAN, NORMAN A. SLADE, ROBERT M. TIMM \\ Museum of Natural History and Department of Systematics $\mathcal{E}$ Ecology, The University of \\ Kansas, Lawerence, Kansas 66045-2454, U.S.A.
}

\author{
AND \\ CHERYL A. SCHMIDT \\ Department of Biological Sciences, Texas Tech University, Lubbock, Texas 79409-3131, \\ U.S.A.
}

Received June 1993, revised manuscript accepted for publication March 1994.

Amazonian lowland rain forests are complex thrce-dimensional formations consisting of a variety of arboreal and terrestrial habitats. The small nammal faunas, particularly of arboreal habitats, are poorly studied, and field research generally has been limited to a few famal inventories. We sampled the terrestrial and arboreal small mammal fauna in two floodplain forest study zones at Reserva Cuzco Amazonico, southeastern Peru, by removal trapping for 12 consecutive days in dry (June-July 1989) and rainy seasons January-February 1990\}. Nineteen taxa of marsupials and rodents were captured. Small mammals were more abundant in the rainy season than in the diy season, but the relative proportions of the 11 most abundant species remained stable between seasons and study zones. Most species showed no decline in capture rates through the 12-day period, indicating that either population densities were high or aninals were quite mobile. The small mammal fauna exhibited strong vertical stratification; among the 11 most abundant specics, four exhibited strong biases toward terrestrial and five toward above-ground captures. The distinct arborcal snall mammal community is grossly underrepresented if traps are placed only at ground level.

ADDITIONAL KEY WORDS:-biodiversity - ecology - S. America - rain forest.

\section{CONTENTS}

Introduction

Study site

Methods

Results

Trapping results

Distribution of above-ground captures

Estimates of population size

Sex ratio

Adequacy of sampling period

Corresponding author: Robert Tinm. 
Discussion

Acknowledgements .

References.
16

19

19

\section{INTRODUGTION}

Tropical regions may contain as many as two-thirds of all species of organisms on Earth (May, 1988), and it has been estimated that at least half of the planet's biodiversity occurs in tropical rain forests (Myers, 1988). Unfortunately, because of the continuing high rate of deforestation in tropical environments (Raven, 1988), many habitats will be lost before we have an understanding of their plant and animal communities. Deforestation and the resulting biodiversity crisis have increased awareness and interest in conservation of natural tropical habitats (Wilson, 1988, 1992), but rational conservation practices require a basic understanding of native fauna and flora. Tropical rain forests are not single, homogeneous, biotic formations (Gentry, 1990); the biodiversity of these areas must be understood on a local, as well as a regional, level.

Lowland, tropical rain forests in the Amazon Basin provide diverse habitats to a wide array of small mammals. More than a decade ago Mares (1982, 1986) and Pine (1982) expressed concern over the lack of research in the Neotropics, particularly South America, and our lack of knowledge of the composition and ecology of its mammalian faunas. Several recent studies document high mammalian diversity in tropical rain forests (Fonseca \& Kierulff, 1989; Stallings, 1989; Timm et al., 1989; Woodman et al., 1991). Whether the mammalian diversity in rain forests, specifically in the Amazon Basin, is exceptional for the tropics is the subject of current controversy (Chesser \& Hackett, 1992; Mares, 1992a, b; Pimm \& Gittleman, 1992). This controversy centers around definitions of the biomes being compared and scales of comparison (size of region and local diversity). This and earlier work (Patterson, 1986) emphasize the importance of understanding variation within communities.

Increased attention focused on the Neotropics has led to important pioneering studies in the Amazon Basin (Emmons, 1982, 1984, 1987, 1991; Handley, 1976; Janson \& Emmons, 1990; Malcolm, 1990; Terborgh et al., 1984; Woodman et al., 1991), yet the mammalian faunas of most habitats in Amazonian lowland forests remain virtually unstudied, lacking even basic inventories. Three dimensional complexity is characteristic of rain forests, and each of the dominant groups of small mammals in these communities (didelphid and marmosid marsupials, and cricetid and echimyid rodents) contains arboreal and terrestrial members. Nevertheless, arboreal species have been unevenly and inadequately studied.

In 1989-1990 the Neotropical Biological Diversity Program (BIOTROP) of the University of Kansas Museum of Natural History, working in collaboration with the Asociación de Ecología y Conservación (ECGO), Lima, the Museo de Historia Natural of the Universidad Nacional Mayor de San Marcos, Lima, and the Missouri Botanical Garden, completed an initial study of the flora and fauna of Reserva Cuzco Amazónico, southeastern Peru (Davis et al., 1991; Duellman \& Koechlin, 1991; Duellman \& Salas, 1991; Woodman et al., 1991). To sample the mammalian fauna at this site, we established a collecting protocol that focused on rapid assessment of small terrestrial and arboreal mammal species and permitted direct, quantifiable comparison of faunas among 
habitats and among sites. In addition, we collected data that permit us to determine the size, age and sex structure of populations within the mammalian community.

The purpose of this paper is to describe the structure of the small mammal community at Cuzco Amazónico and examine the temporal and spatial variability at this single locality. We compare community structure between two study zones in minimally-disturbed, primary forest; between the wet season and the dry season; and between terrestrial and arboreal habitats. Our studies provide new information about the composition of mammalian communities in the Neotropics and will assist in planning future studies addressing biodiversity and community structure of small mammals in the tropics.

\section{STUDY SITE}

We worked at Reserva Cuzco Amazónico, a wildlife reserve along the north bank of the Río Madre de Dios, $14 \mathrm{~km}$ east of Puerto Maldonado, Tambopata Province, Madre de Dios Department, southeastern Peru $\left(12^{\circ} 33^{\prime} \mathrm{S}, 6^{\circ} 03^{\prime} \mathrm{W}\right.$; Fig. 1). The 10000 ha protected area is managed by José E. Koechlin, who operates a tourist lodge, Albergue Cuzco Amazónico, near the southwest corner of the reserve. The reserve is located near the transition between the Humid Tropical Forest and Dry Tropical Forest in the Holdridge system (Tosi, 1960), and the vegetation is typical of the region. Most of the reserve is relatively undisturbed, evergreen, lowland forest, with as many as 1400 species of angiosperms, including 400 species of trees (A. H. Gentry, personal communication). The elevation of Cuzco Amazónico is about $200 \mathrm{~m}$ with little topographic relief. A detailed site description of Cuzco Amazónico, including climate, vegetation, soils, history, and maps was provided by Duellman \& Koechlin (1991).

The mammal fauna at Cuzco Amazónico is diverse. Woodman et al. (1991) identified 100 species from this locality and suggested another 30 species (mostly bats) that could occur there. The species confirmed from the site included 9 marsupials, 43 bats, 7 primates, 5 xenarthrans, 1 lagomorph, 23 rodents, 9 carnivores, 1 perissodactyl, and 2 artiodactyls.

\section{METHODS}

We trapped in two $500 \times 340 \mathrm{~m}$ study zones (Fig. 2), one c. $800 \mathrm{~m} \mathrm{WNW}$ of the lodge buildings in floodplain forest (Zone 1) and one c. $650 \mathrm{~m} \mathrm{NE}$ of the tourist camp in floodplain forest adjacent to seasonally inundated swamp forest (Zone 2). These two zones are not substantially different vegetatively, except for the southeast corner of Zone 2, which projected into swamp forest (A. Gentry, personal communication). The swamp forest was inundated seasonally or semipermanently, and its understory was more open than the floodplain forest; there were fewer ferns, less herbaceous ground cover, and more Heliconia and Calathea (Duellman \& Koechlin, 1991). Much of Zone 2 also was covered temporarily by standing water during part of the wet season. Access to each zone was from trails set parallel to the zone's boundaries. We trapped for small mammals along two, 500 m-long trails, designated $\mathbf{E}$ and $\mathrm{U}$, in each zone. Within each zone, the two trails were $320 \mathrm{~m}$ apart, except in northeastern 


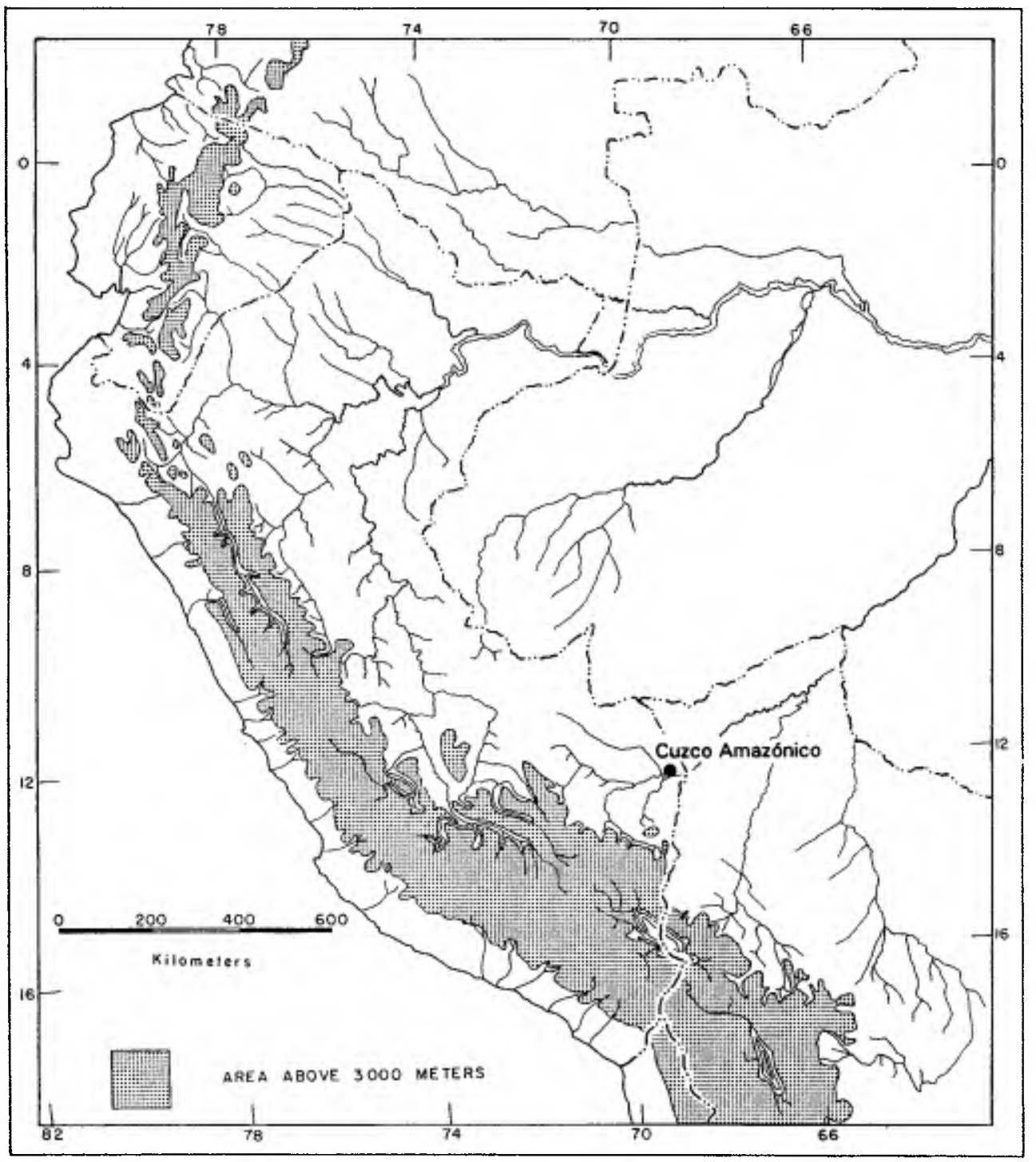

Figure 1. Location of Cuzco Amazónico in southeastern Peru.

Zone 2, where $\mathbf{U}$ trail converged toward $\mathbf{E}$ trail to avoid extending into swamp forest. Each trail bisected twenty-five $20 \times 20$-m contiguous quadrats, for a total of 100 quadrats sampled in the two zones.

One trapping station, consisting of two Victor snap-type rat traps and two collapsible Sherman live-traps $(8 \times 9 \times 23 \mathrm{~cm})$, was placed within each of the $20 \times 20-\mathrm{m}$ quadrats. At each station one snap- and one live-trap were placed on the ground and one of each was secured above the ground. All four traps were placed within one horizontal meter of each other. Height of traps above ground was recorded to the nearest $\mathrm{dm}$. We trapped along each trail in the 


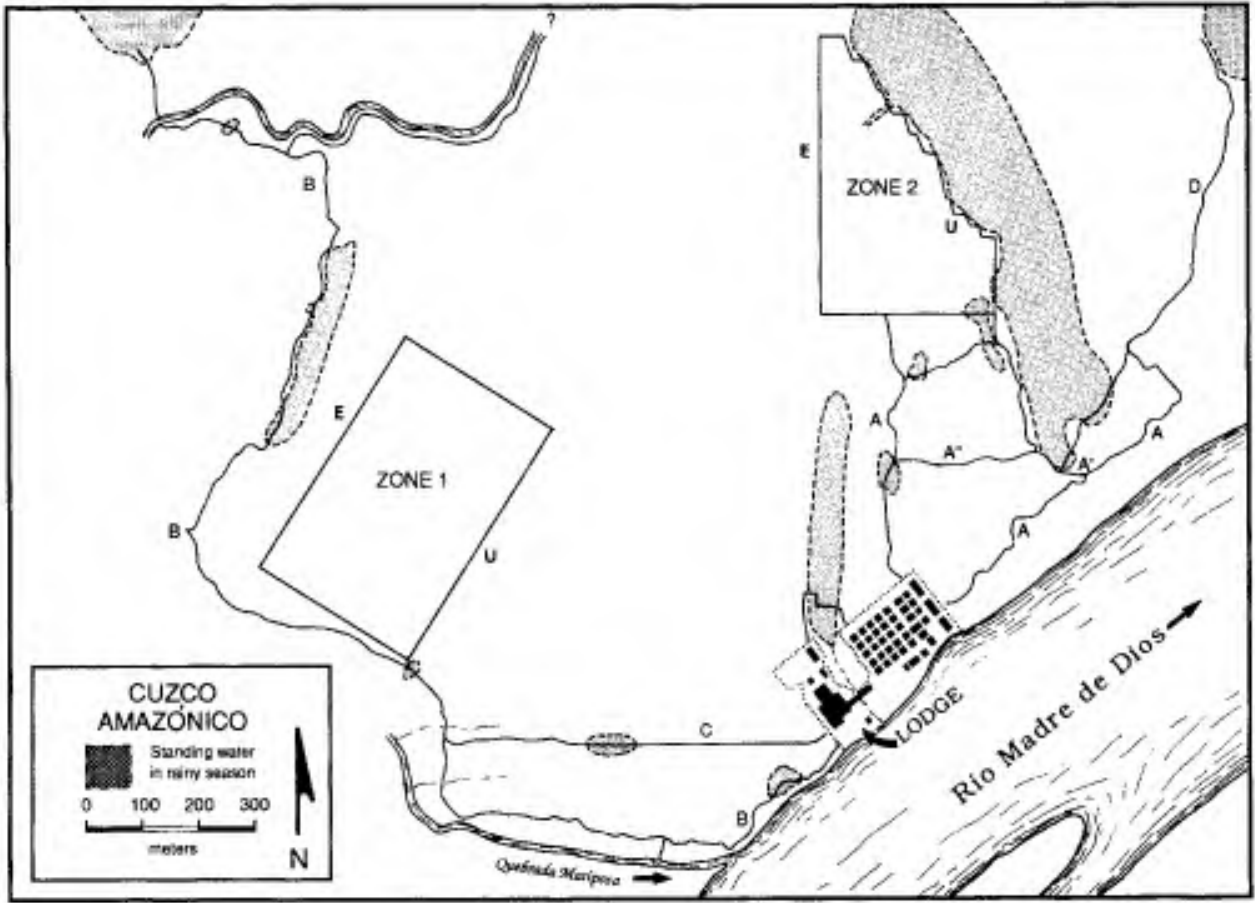

Figure 2. Locations of zones and trails at Cuzco Amazónico. Printed with permission of Occasional Papers of the Museum of . Natural Histony, The University of Kansas.

study zones for 12 consecutive days, once during the dry season (12 June to 10 July) and once during the wet season (19 January to 15 February) for a total of 9600 trapnights. For additional details on trapping methodology, see Woodman et al. (1991). All animals captured were removed from the zones and retained as specimens; these are deposited at the Museo de Historia Natural of the Universidad Nacional Mayor de San Marcos and The University of Kansas Museum of Natural History.

Observed frequencies of captures were compared to distributions of traps using Chi-square goodness of fit tests $\left(X^{2}\right)$. For dichotomous comparisons with $n \geqslant 10$ captures, we used Chi-square tests with a single degree of freedom; when $n<10$ we calculated probabilities of Type I errors directly from a binomial distribution. In all statistical analyses a probability of $P \leqslant 0.05$ was considered significant.

\section{RESULTS}

\section{Trapping results}

Small mammals at Cuzco Amazónico proved to be abundant and diverse. In the two study zones we captured a total of 505 individuals of six species of marsupials and 15 species of rodents (Tables 1-4). In all analyses of our trapping data we combined the three species of Proechimys because these species 
were difficult to distinguish either morphologically or ecologically. Rhipidomys sp. represents a single, undescribed species (C. Tribe, personal communication). Four mid-sized species, Didelphis marsupialis, Metachirus nudicaudatus, Isothrix bistriata and Sciurus ignitus, were represented only by juveniles. Adults of these species are much too large to be captured by our traps. Although captures of these species are included in our analyses, they are not considered to represent true estimates of their abundance or of their importance in the total mammal community. Both D. marsupialis and $S$. ignitus commonly were sighted in the two study zones. Three marsupial species (Caluromys lanatus, Monodelphis adusta and Philander opossum) and eight species of rodents (Agouti paca, Coendou bicolor, Dasyprocta variegata, Myoprocta pratti, Nectomys squamipes, Oligoryzomys microtis, Rattus rattus and Sciurus spadiceus) known to occur at Cuzco Amazónico (Woodman et al., 1991) were not captured in traps set in the study zones. Seven of these species are too large to be sampled using our trapping methodology. Monodelphis adusta was represented by only a single individual, captured in a pitfall near the edge of Zone 2. Nectomys squamipes was an uncommon rodent restricted to swamp forest habitat, and Oligoryzomys microtis and Rattus rattus were taken only in buildings. Woodman et al. (1991) hypothesized that four additional species of marsupials and rodents might occur at the site, but all are too large to be captured by our traps. All further discussion regarding the small mammal fauna concerns only those species captured in the study zones.

Significantly more animals were captured during the rainy season than in the dry season (Tables $1-4 ; X^{2}=10.553$, d.f. $=1, P<0.01$ ). Despite this, there was no significant difference between seasons in relative abundance of the dominant elements of the community, i.e. the 11 most abundant species $\left(X^{2}=15.626\right.$, d.f. $\left.=10, P=0.11\right)$.

Captures were evenly distributed between Zone $\mathrm{l}(n=255)$ and Zone 2 $\left(n=250 ; X^{2}=0.032\right.$, d.f. $\left.=1, P=0.86\right)$. There was a significant difference in species composition between the two study zones $\left(X^{2}=19.356\right.$, d.f. $=10$, $P=0.04)$, but this difference was entirely attributable to one species, Oryzomys nitidus, which was much more common in Zone 1 than Zone 2 (both seasons combined). When we excluded $O$. nitidus from the comparison, the difference in species composition between the zones was not significant $\left(X^{2}=10.9 \mathrm{I}\right.$, d.f. $=9, P=0.28$ ).

In comparing arboreal and terrestrial captures, we found that many more animals were taken on the ground $(n=338)$ than above ground $(n=167$; $X^{2}=57.903$, d.f. $=1, P \ll 0.01$ ), even though the traps were evenly distributed. Compositions of terrestrial and arboreal communities were strikingly different $\left(X^{2}=299.29\right.$, d.f. $\left.=10, P \ll 0.01\right)$. Among the 11 most abundant species tested individually, only Marmosops noctivagus was captured equally often in arboreal and terrestrial traps. Oryzomys yunganus also showed no statistical difference between probabilities of capture in the two sets of traps, but numbers of captures were extremely small $(n=7)$. The genus Oryzomys generally is considered to be predominantly terrestrial, and both above-ground captures of this species were below $\mathrm{l} \mathrm{m}$ on fallen, horizontal logs. All other species were captured significantly more frequently either in traps set on the ground (Oryzomys capito, Oryzomys nitidus, Proechimys and Neacomys spinosus) or above the ground (Oecomys bicolor, Micoureus regina, Mesomys hispidus, Rhipidomys sp. and Oecomys tapajinus; Tables 1-4). 


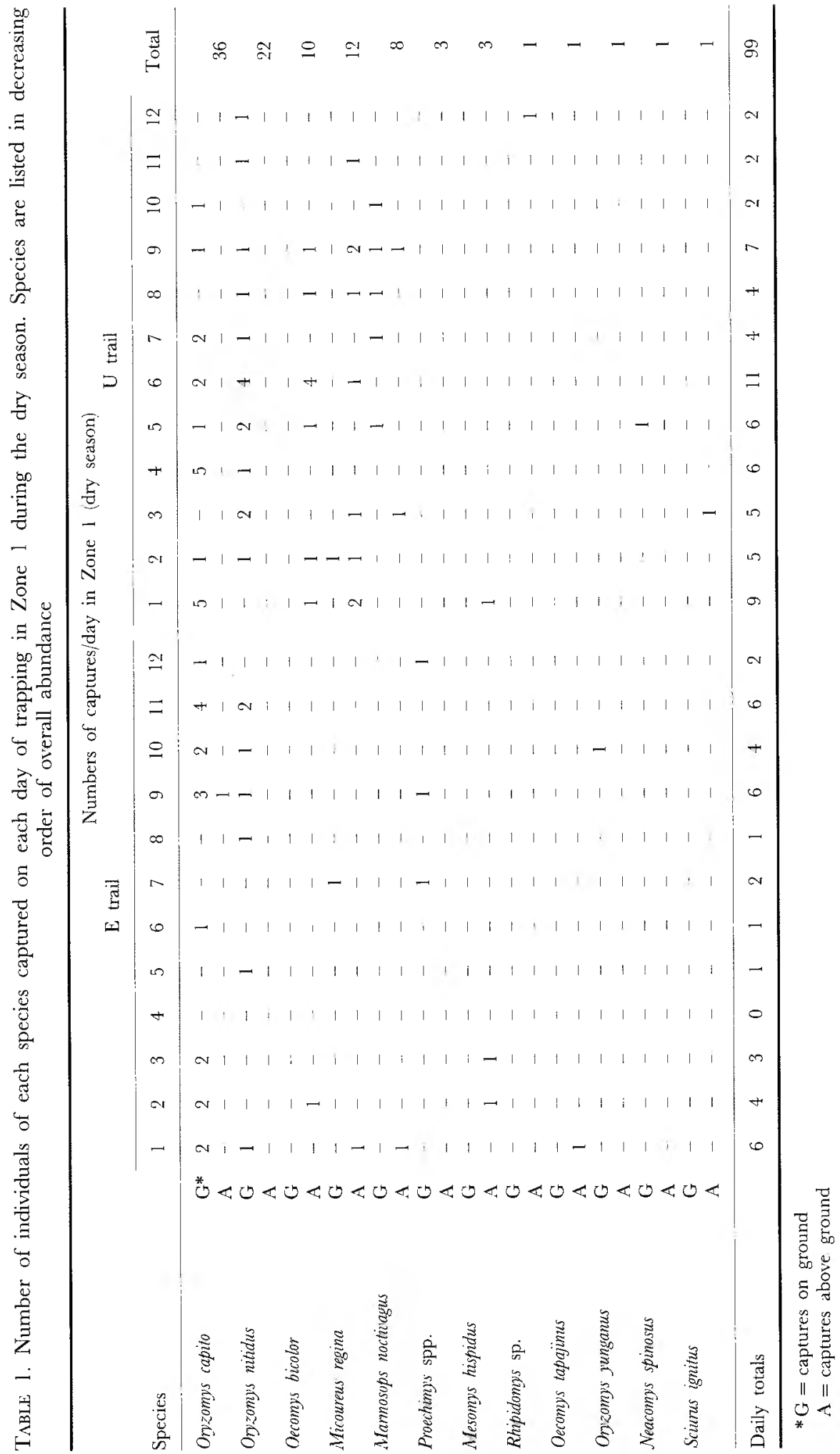




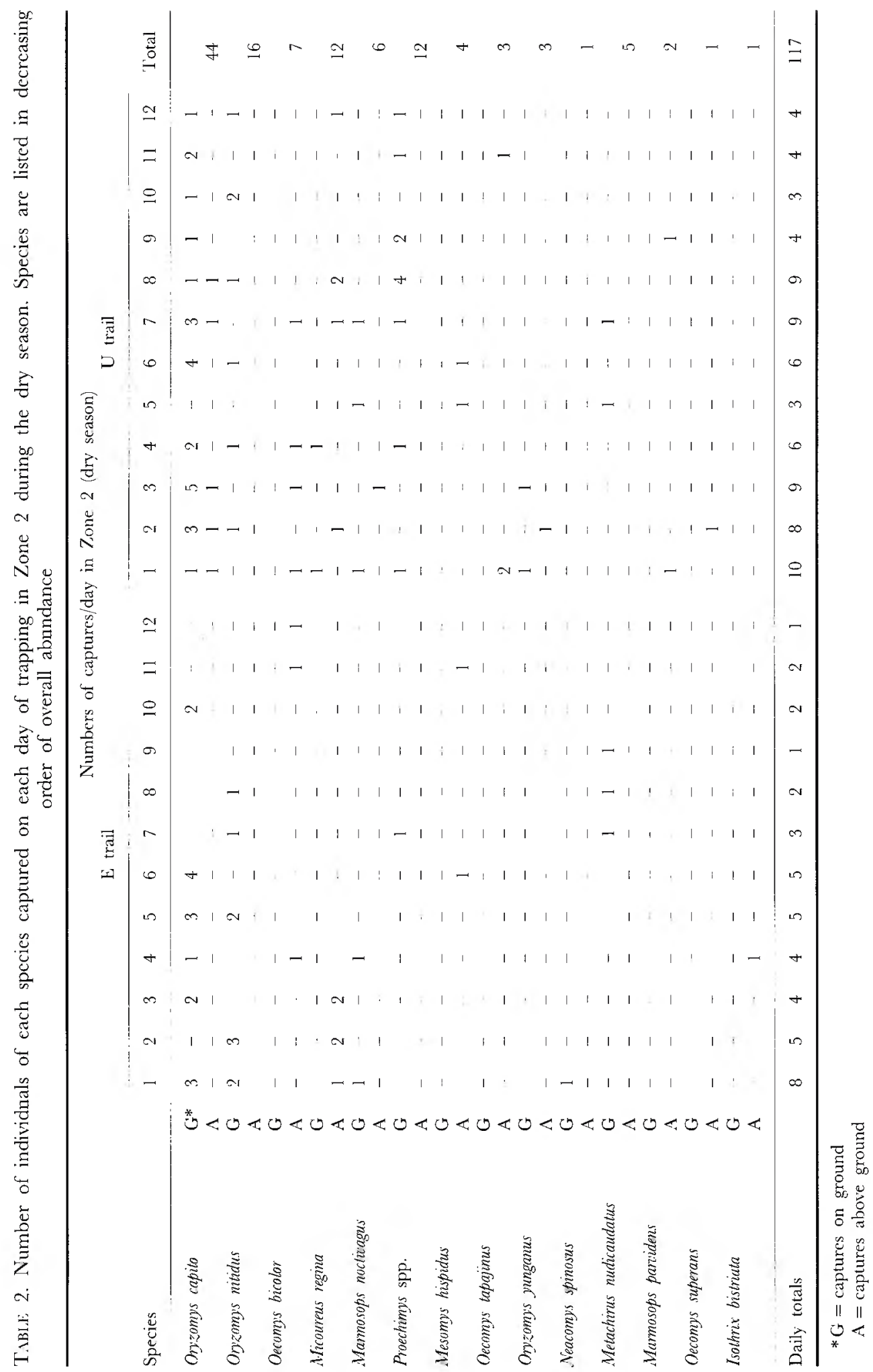




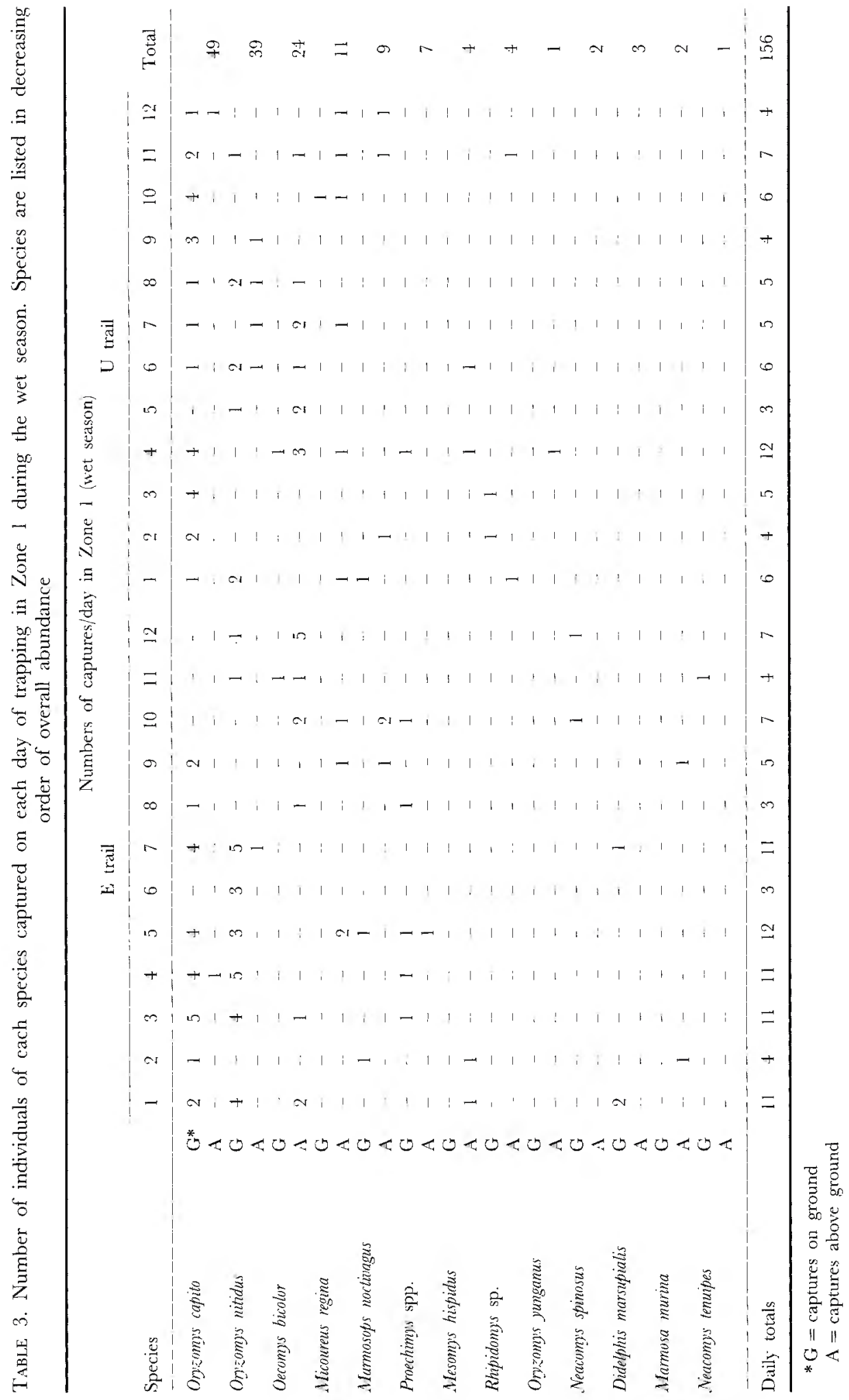




\section{Distribution of above-ground captures}

We examined height of capture for each species having six or more captures above ground (Tables 1-4). During the dry season, we had 296 traps at known heights; of these $152(48.65 \%)$ were above ground level, ranging in height from 0.3 to $2.0 \mathrm{~m}$. During the rainy season, 203 of 400 traps $(50.75 \%)$ were set above the ground at heights ranging from 0.2 to $2.8 \mathrm{~m}$. Vertical distributions of traps and above-ground captures were compared using the KomolgorovSmirnov test of cumulative distribution functions.

Only two species showed any evidence of vertical stratification in their aboveground captures. Micoureus regina tended to be caught above l m; 28 of 30 individuals $(93 \%)$ were taken above this height, although only $66 \%$ of aboveground traps were set above $1 \mathrm{~m}$. However, this was not statistically significant $(D=0.210, n=30, P>0.10)$. Arboreal captures of the generally terrestrial Oryzomys capito were concentrated below $\mathrm{l} \mathrm{m}(D=0.782, n=16, P \leqslant 0.01)$. Most captures of this species above ground (10 of 16 captures), and of the other two species of Oryzomys (5 of 7 captures), were on fallen, horizontal logs.

\section{Estimates of population size}

Absolute numbers of individuals of each species captured (Tables 1-4) provide a general idea of the relative abundance of each species in the community at Cuzco Amazónico. However, these are imprecise assessments because the relationship of this measurement to the overall population size is unknown without additional knowledge about each species. For example, 12 days of trapping may sample the entire effective population of one species, whereas it may sample only a small portion of another species because of differences in territory size, probability of capture and behaviour. Therefore, we attempted to estimate population sizes from rates of depletion through time.

Two methods were used to estimate the total numbers of animals available for capture along the trails. We first fit linear regressions to plots (Leslie graphs; Overton, 1971) of captures on day $i, Y$, versus cumulative captures through day $i-1, X$. The $X$ intercepts of the plots are estimates of population size (Hayne, 1949). We also estimated population size by fitting maximum likelihood models from program CAPTURE using the removal (model $\mathbf{M}_{\mathrm{bh}}$ ) option (White et al., 1982). This approach allows testing for homogeneous probabilities of capture through time, which is an assumption of the regression method.

We used Hayne's (1949) method and CAPTURE to estimate numbers of animals by season, first for the entire community, then for the seven most abundant species (total number of captures $>15$; Tables 1-4) and for Rhipidomys in the rainy season. Trapping along each of the four trails appeared to sample different effective populations. To obtain testable sample sizes for each species, we pooled data from Zone 1 and Zone 2 together in these analyses, because we demonstrated previously that there was no difference in relative species composition between zones, except for Oryzomys nitidus. However, to avoid potential differences related to temporal variation in conditions (e.g. weather, moonlight), we tested the results of trapping on $\mathbf{E}$ trails in Zone 1 and Zone 2 (days $1-12$ ) separately from $U$ trail trapping data (days 13-24).

Total captures per day decreased significantly with cumulative captures along 


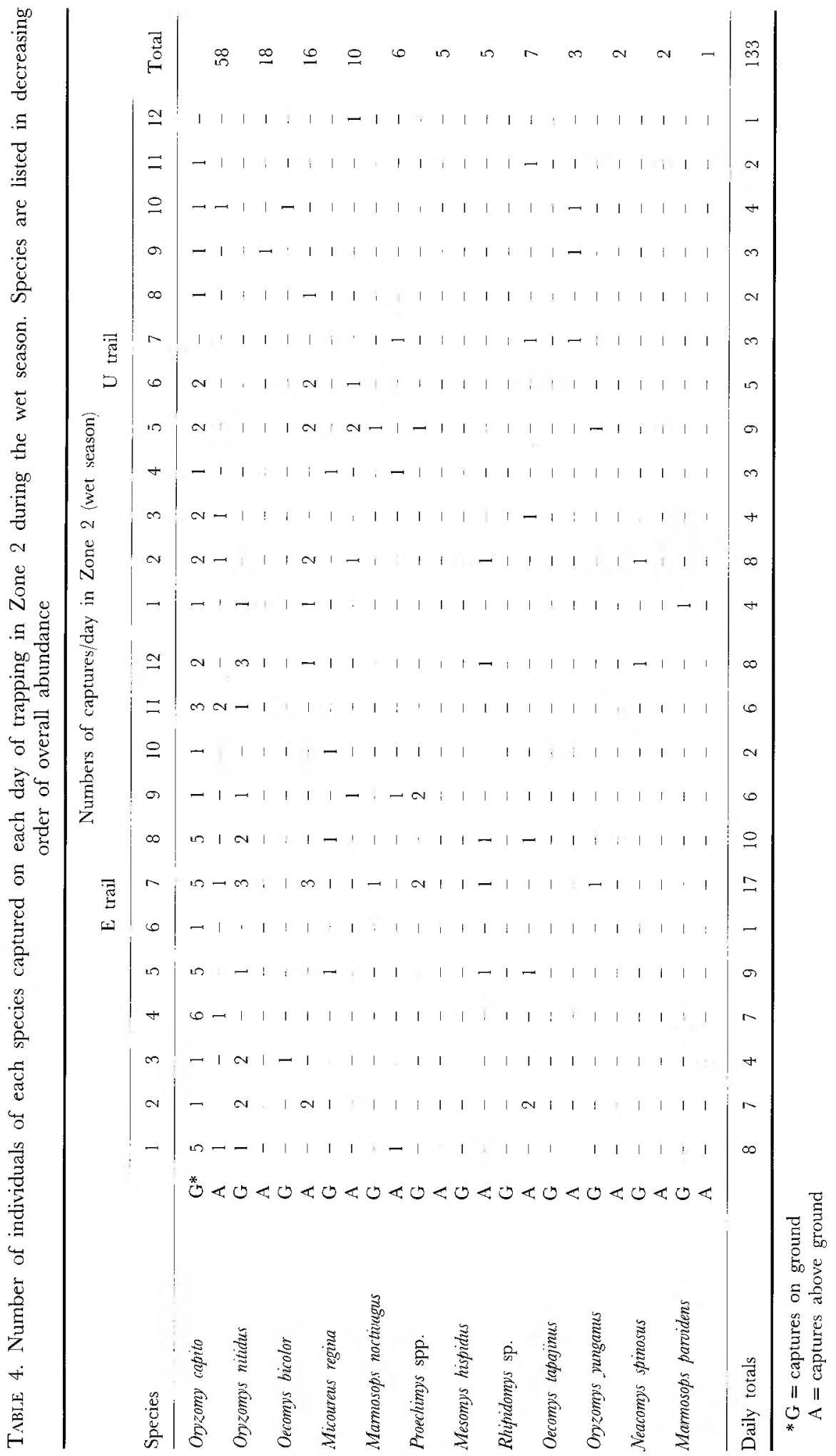



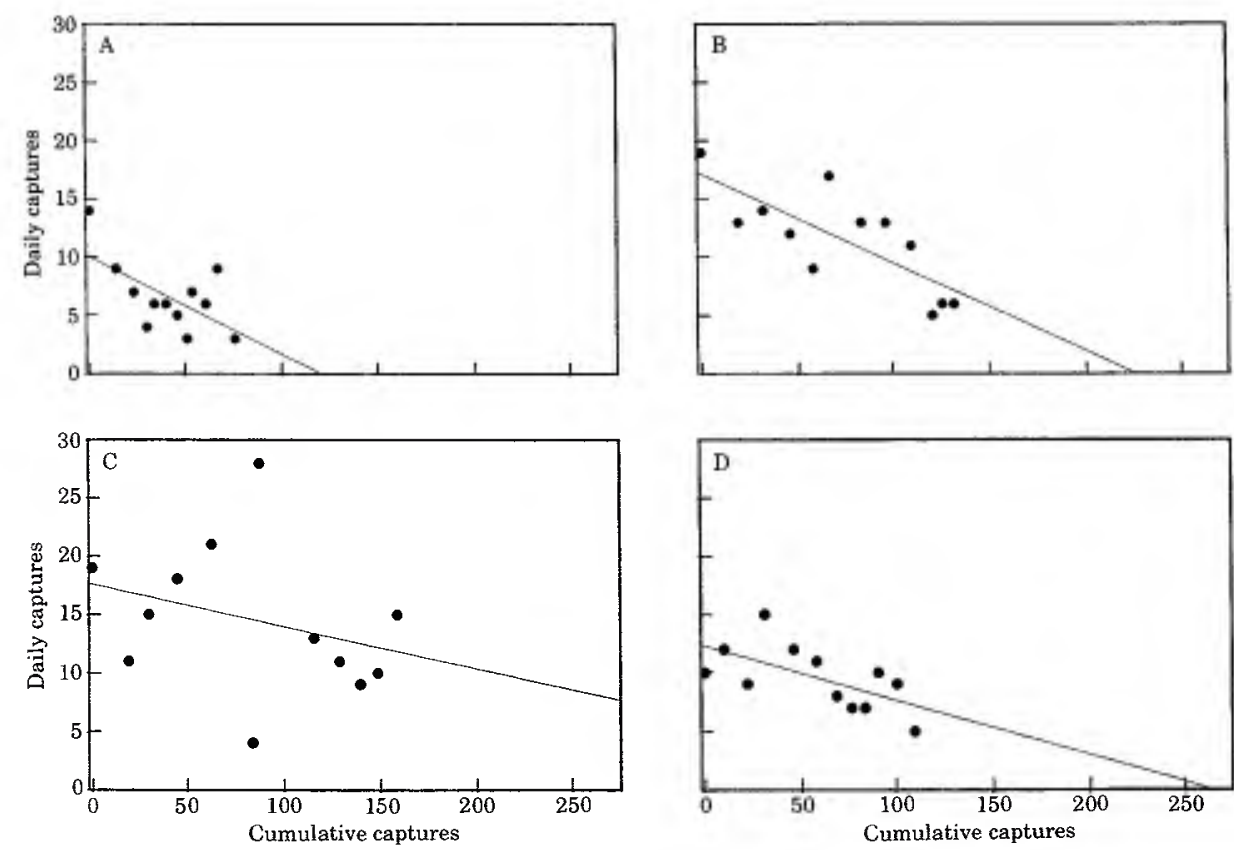

Figure 3. Regressions of the total cumulative number of captures per day on the number of captures per day along $\mathrm{E}$ trails (A) and $\mathrm{U}$ trails (B) during the dry season, and along $\mathrm{E}$ trails $(\mathrm{C})$ and $\mathbf{U}$ trails (D) during the wet season.

the E trails during the dry season $\left(\hat{Y}=10.0-0.083 X ; P=0.037, R^{2}=36.8 \%\right.$; $n=12$; Fig. 3A). The absolute value of the slope was an estimate of the probability of capture, and the $X$ intercept (120) was an estimate of total numbers in the community along the two trails (Hayne, 1949). Corresponding estimates from CAPTURE were $0.07 \mathrm{l}$ and $135 \pm 40$ ( $\pm \mathrm{SE}$ ), respectively. Regression $\left(\hat{Y}=17.1-0.076 X ; P=0.003, R^{2}=59.8 \% ; n=12 ;\right.$ Fig. 3b) produced an estimate of 226 animals along the $U$ trails in the dry season. Analysis with CAPTURE estimated capture probability as 0.082 and numbers as $214 \pm 38$. During the rainy season, the regression estimate of numbers on the $\mathrm{U}$ trails $\left(\hat{Y}=12.3-0.046 X ; \quad P=0.031, R^{2}=38.8 \% ; n=12 ;\right.$ Fig. 3D $)$ was 266 . The CAPTURE estimates of probability of capture and population size were 0.052 and $243 \pm 91$, respectively. The negative slope for captures on the $\mathrm{E}$ trails (Fig. $3 \mathrm{C})$ was not significant $(P=0.33)$ and provided no estimate of population size. Program CAPTURE demonstrated that these data did not conform to the model of constant probability of capture assumed by the regression method. Neither did the data from $\mathrm{E}$ trails in the rainy season conform to more complex models of heterogeneous probabilities of capture from CAPTURE (goodness of fit $P=0.045$; tests of heterogeneity for the other three sets of trails tested $P>0.30$ ). Among the trails with temporal patterns that allowed population estimates, actual captures represented between $47 \%$ and $66 \%$ of estimated total numbers in the community.

Among the seven most abundant species, each considered for two trails and two seasons, Hayne's (1949) method for estimating numbers from Leslie plots produced estimated population sizes $(\hat{\mathcal{N}})$ only for Oryzomys capito on the $\mathrm{U}$ trails 
TABLE 5. Estimated numbers of mammals sampled along each pair of trails ( $E$ trails and L trails) in each season from the program CAPTURE

\begin{tabular}{|c|c|c|c|c|}
\hline \multirow[b]{2}{*}{ Species } & \multicolumn{4}{|c|}{ Estimated numbers $\pm S E$} \\
\hline & $\begin{array}{c}\text { Dry season (1989) } \\
\text { E trail }\end{array}$ & $\begin{array}{l}\text { Wet season }(1990) \\
U \text { trail }\end{array}$ & E trail & $\mathrm{U}$ trail \\
\hline Marmosops noctivagus & $3 \pm 0.03$ & $17 \pm 11.51$ & - & $9 \pm 4.06$ \\
\hline Mesomys hispidus & $\cdots$ & -- & $7 \pm 2.23$ & - \\
\hline Micourens regina & $7 \pm 0.18$ & $22 \pm 7.18$ & - & - \\
\hline Oecomys bicolor & -- & $14 \pm 2.23$ & - & $26 \pm 8.16^{b}$ \\
\hline Oryzumys capito & $76 \pm 61.04$ & $56 \pm 7.40$ & $68 \pm 3.76^{\mathrm{d}}$ & $102 \pm 79.62$ \\
\hline Opyzomys nitidus & $20 \pm 6.39$ & - & $67 \pm 21.75^{\mathrm{h}}$ & $25 \pm 19.74^{\mathrm{b}}$ \\
\hline Rhipidmyss sp. & 一 & -- & - & $7 \pm 1.72$ \\
\hline
\end{tabular}

${ }^{a} P<0.05$ for homogeneity of probalility of capture over 12 days.

${ }^{\text {h }} 0.05<P<0.15$ for lack of fit of REMOVAL model of CAPTLRE.

in the rainy season $\left(\hat{\mathcal{N}}_{\mathrm{UR}}=60\right)$ and Micoureus regina along $\mathrm{E}$ trails in the dry season $\left(\hat{\mathcal{N}}_{\mathrm{ED}}=7\right.$, the number actually captured). These population estimates were within one standard error of the maximum likelihood estimates from CAPTURE (Table 5). For Oryzomys capito, $\hat{\mathcal{N}}_{\mathrm{UR}}=71 \pm 30$ from CAPTURE using a model of heterogeneous capture probabilities that fit better $(P=0.45)$ than the homogeneous model $(P=0.39)$. Maximum likelihood methods produced many more estimates of population size (goodness of fit $P>0.05$ ) than did regression even when the assumption of homogeneous capture probabilities was valid (Table 5). For Oryzomys capito and Micoureus regina, estimated probabilities of capture were 0.119 and 0.350 from regression, and 0.043 and 0.368 from CAPTURE. The proportion of estimated numbers actually captured varied from 0.41 to 1.0 for the 16 maximum likelihood population estimates.

We hypothesized that movements of younger (smaller) individuals into vacated territories was responsible for heterogeneous probabilities of capture and our failure to find significant decreases in captures within species after removal of animals. To test the possibility that older (larger) animals were captured earlier, we carried out an ANOVA on mean body weight for each day for each of the six most abundant species, segregated by season. Sample size for the seventh most frequently captured species, Mesomys hispidus, was too small for an ANOVA. None of the species tested showed significant variation among mean body weights over time, suggesting that both younger animals and adults were captured throughout the course of trapping in each season.

\section{Sex ratio}

We examined sex ratio for the eight most frequently captured species in each season by comparing the observed proportion of males to 0.5 . Twentyone specimens of unknown sex were excluded from this analysis. In only one instance was the sex ratio significantly different from $1: 1$; during the rainy season there was a significant excess of male Oryzomys nitidus $(n=35$ males, 21 females; $P=0.0012$ ). In the dry season we also captured more male than female $O$. nitidus, but the difference was not significant $(n=21$ males, 14 females; $P=0.3106)$. 

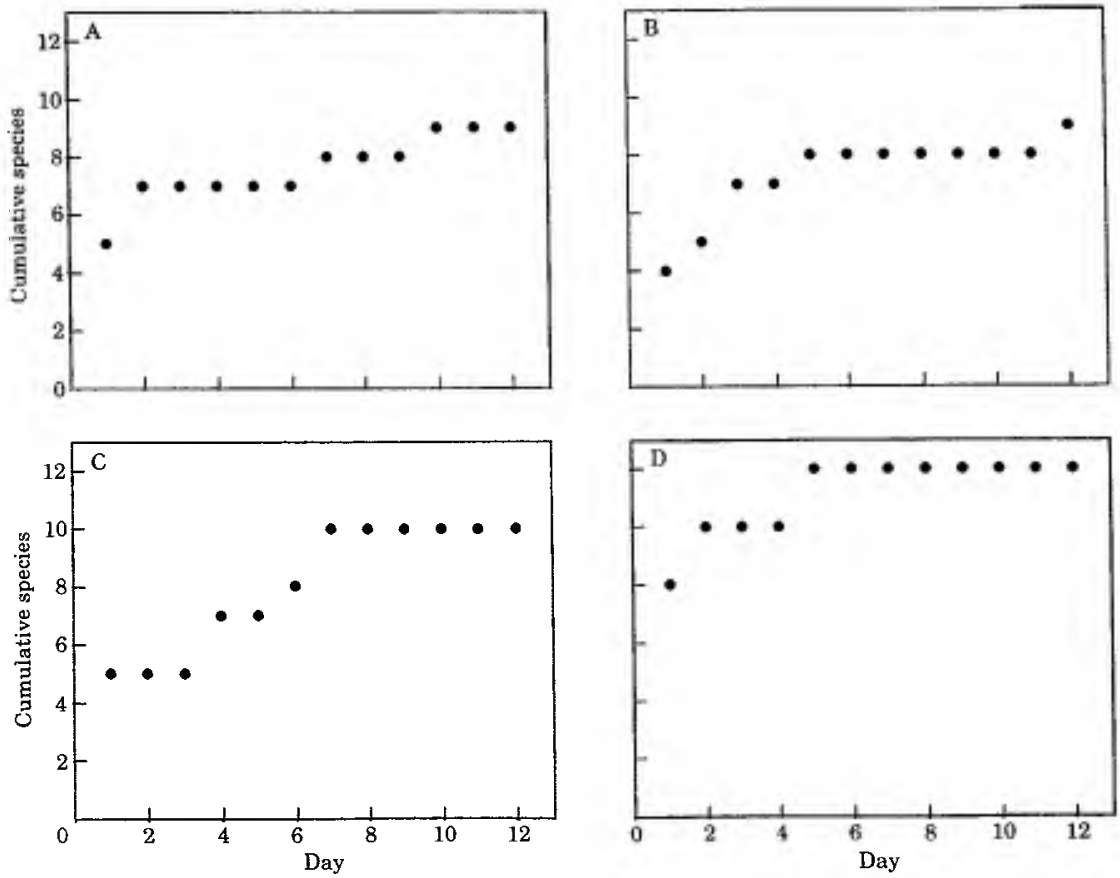

Figure 4. Plots of cumulative numbers of species captured during the dry season by day of trapping along $\mathbf{E}$ trail $(\mathrm{A})$ and $\mathrm{U}$ trail $(\mathrm{B})$ in Zone $\mathbf{l}$, and along $\mathbf{E}$ trail $(\mathrm{C})$ and $\mathrm{U}$ trail (D) in Zone 2.

\section{Adequacy of sampling period}

To determine whether 12 days of trapping along each trail was necessary to sample the small mammal diversity at Guzco Amazónico, we constructed species accumulation curves (Figs 4, 5) for each trail by plotting cumulative number of species by day of trapping. Results from each season were considered separately. To determine if there were patterns in timing of captures for individual species, we examined the chronological distribution of captures for each taxon (Tables 3, 4). For this analysis, captures along $\mathrm{E}$ trails were combined and captures along $U$ trails were combined, irrespective of zone. Data for each season were considered separately. Species that were scarce, but easy to capture should have been taken within the first few days of trapping. Species that were scarce and difficult to capture should not have been captured early on.

A total of 16 species was captured during the dry season, but no more than 12 species were captured along any one trail. Plots of cumulative captures for each trail (Fig. 4A-D) show the sharpest rise on the first day of trapping, followed by a gradual increase in species, and then a general levelling off. In Zone 1, all but one species (Rhipidomys sp.) ultimately captured along a trail were taken by day 7 , and in Zone 2 all species had been taken by that day.

Fifteen species were captured during the wet season, but again no more than 12 species were taken along a single trail. Patterns were similar to those in the dry season (Fig. 5A-D). In Zone 1, all species ultimately captured along $\mathrm{U}$ trail were taken by day 4 . However, along $\mathrm{E}$ trail, all species were not 

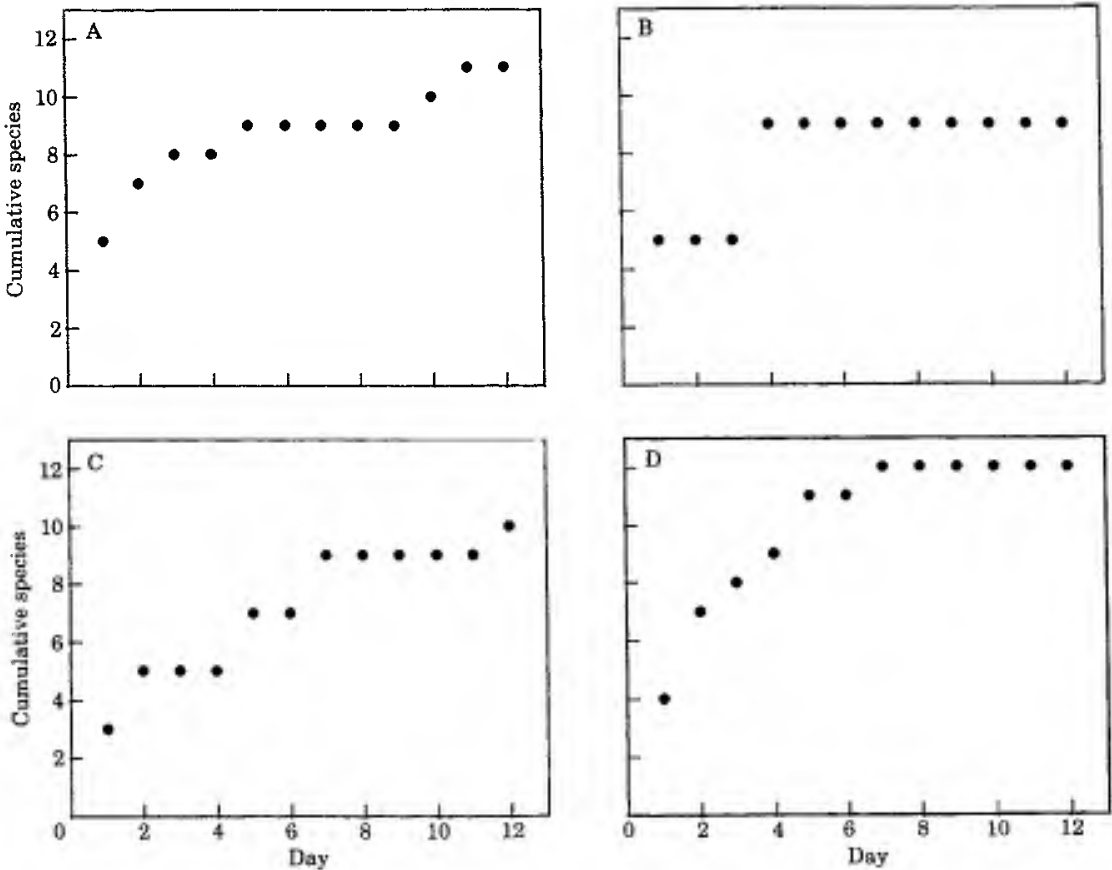

Figure 5. Plots of cumulative numbers of species captured during the wet season by day of trapping along $\mathrm{E}$ trail $(\mathrm{A})$ and $\mathrm{U}$ trail $(\mathrm{B})$ in Zone 1 , and along $\mathbf{E}$ trail $(\mathrm{C})$ and $\mathbf{U}$ trail $(\mathrm{D})$ in Zone 2.

taken until day 11. On day 7, all but two species (Neacomys spinosus $\mathcal{E}^{\circ} \mathcal{N}$. tenuipes) had been captured. In Zone 2, all but one species ( $\mathcal{N}$. spinosus) were taken along $\mathrm{E}$ trail by day 7 , and all species ultimately captured had been trapped along $\mathrm{U}$ trail by that day.

To look at species captured over the site as a whole, we combined data from all four trails and constructed species accumulation curves for each season. The resulting plots (Fig. 6) are similar to the individual plots for the trails, although the initial rise after the first day of trapping is greater. During the dry season, all but one species had been captured by day 5. The last species, Rhipidomys sp., was not taken until day 12. In the wet season, all but one species had been captured by day 7. The final species, Neacomys tenuipes, was taken on day 11 . In no case did trapping in one zone during one season yield more than $75 \%$ of all species ultimately taken at the site.

There was no obvious difference in relative abundances of species after 7 days of trapping versus after 12 days of trapping. Because of the lack of independence between these two trapping periods (7 days vs. 12 days), we could not test them directly. Instead, we carried out $X^{2}$ comparisons of the first 7 days and the last 5 days. Although data along $E$ trails and along $U$ trails were combined as in the previous analysis of community structure, sample sizes of some species were small. During the dry season, relative abundances during the two trapping periods did not show a significant difference along the E trails $\left(X^{2}=6.742, P=0.345\right)$, but were significantly different along the $\mathrm{U}$ trails $\left(X^{2}=16.233, P=0.013\right)$. The difference in relative abundances along the 


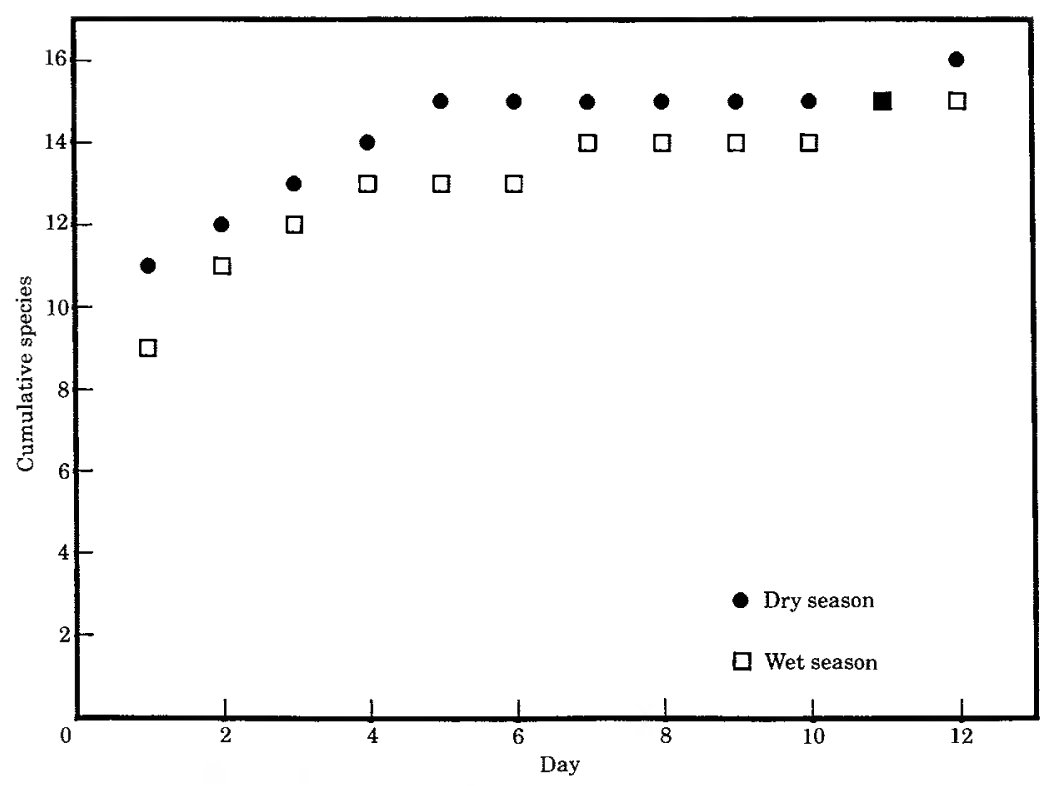

Figure 6. Plot of cumulative numbers of species captured during the dry season (dots) and in the wet season (open squares) in both zones by day of trapping. Data from $\mathrm{E}$ trails and $\mathrm{U}$ trails are considered together despite heterogeneity in actual trapping dates.

$\mathrm{U}$ trails was due entirely to one taxon, Proechimys, which had more captures than expected during the last 5 days. Relative abundances of species were significantly different along $\mathrm{E}$ trails $\left(X^{2}=13.090, P=0.042\right)$ during the rainy season, but not along $U$ trails $\left(X^{2}=5.827, P=0.443\right)$. The difference along the $\mathrm{E}$ trails in this season was due to an excess of captures of Micoureus regina and Oecomys bicolor for days 8 through 12 .

\section{DISCUSSION}

Community structure of the most common species of terrestrial and arboreal small mammals in Zone $\mathrm{l}$ and Zone 2 habitats at Cuzco Amazónico was nearly identical, indicating that both zones were occupied by a homogeneous community. The composition of the community remained stable in the two zones through both seasons, despite significant increases in abundance or probability of capture during the rainy season. The minor vegetational and physical differences between Zone $\mathrm{l}$ and Zone 2 at Cuzco Amazónico had little influence on the arboreal and terrestrial small mammal communities. In temperate North America, variation between years in abundances and relative abundances of members of small mammal communities are well documented (e.g. Chesson \& Cole, 1986; Swihart \& Slade, 1990), and we would expect to see this in Amazonian rain forest communities as well. Our data are for only a single year, and we are unaware of any other systematic studies of sufficient duration to address this issue.

Although the dominant species of small mammals at Cuzco Amazónico show lateral homogeneity, there is a strong vertical heterogeneity dividing the fauna 
into distinct arboreal and terrestrial communitics. Like the mammal community as a whole, the arboreal and terrestrial communities also remain stable despite seasonal variation in abundances. The terrestrial community is represented by greater numbers of captures, but this appearance of greater abundance may be due to the fact that we were able to sample only a small portion of the threc-dimensional, above-ground environment. Similar numbers of species were present in both the terrestrial and arboreal communities. The terrestrial community was dominated by Oryzomys capito and Oryzomys nitidus, which together accounted for nearly $56 \%$ of all captures. These two species were supplemented by Proechimys. The arboreal community was dominated by Oecomys bicolor and Micoureus regina, with lesser numbers of Mesomys hispidus and Rhipidomys sp. The boundary between the two communities was not rigid, as some arboreal specics occasionally ventured onto the ground and some terrestrial species climbed into the lower strata of the above-ground environment. Fallen logs in particular acted as an extension of the terrestrial environment for the three species of Oryzomys, which made up the bulk of terrestrial captures. Handley (1976) also noted that most above-ground captures of Oryzomys capito in Venezuela were on horizontal logs. The use of logs by terrestrial mammals makes it appear as though they climb more often than members of the arboreal community come to the ground (Table 1). Marmosops noctivagus is the only abundant small mammal common to both the terrestrial and arboreal communities. At least seven additional species of small mammals are uncommon to rare members of the community. Oryzomys yunganus, Neacomys spinosus and $\mathcal{N}$. tenuipes probably are predominantly terrestrial; Oecomys superans and $O$. tapajinus are members of the arboreal community; and Marmosa murina and Marmosops parvidens likely spend large amounts of time both on the ground and above ground. The emphasis on tcrrestrial trapping historically maintained by many mammalogists clearly ignores a vital portion of the species diversity present in tropical environments and has in the past appeared to substantiate the false assumption that arboreal mammals werc a rare and unimportant segment of the fauna. In our study, the arboreal habitat sampled was relatively low $(<3 \mathrm{~m})$ because of the difficulty in gaining access to the canopy. It is not unlikely that if the canopy were systematically sampled it would exhibit a community structure distinct from the lower arboreal habitat that we studied.

Our data for individual species from Cuzco Amazónico do not fit the model of population depletion assumed by the Leslie method. The method rcquires constant probabilities of capture and constant sampling effort per day. Even if those assumptions are met, other assumptions of regression are violated, and it is difficult to obtain standard errors for the estimates (White et al., 1982). The more gencral maximum likelihood approach is preferable on both statistical and practical grounds. With removal data, the CAPTURE model necessarily involves bchavioural changes in probability of capture because captured animals are never rccaptured. CAPTURE tests for heterogeneity of capture probabilities among animals or among trapping occasions (these two effects are confounded with removal data). CAPTURE also more frequently produces standard errors for estimated numbers and statistically valid estimates than regressions on Leslie plots. However, neither method produces reliable estimates of population size when captures are sparse or do not decrease somewhat regularly through time. When both methods produced estimates they werc consistent; the regression 
estimates fell within the confidence intervals from CAPTURE. Regardless of the estimation procedure, it is clear that simple numbers of captures provide underestimates of population size and that the degree of underestimation varies with species and season. We also note that the degree of underestimation was not related to number of captures, except that very low numbers of captures $(<20)$ produced estimates close to the actual numbers of captures.

After 12 days of intensive trapping the total small mammal community showed a reduction in size, even though more than $30 \%$ of estimated total numbers remained along each trail, but only two of 28 tests for individual species showed evidence of depletion. This may be because populations were very large, but there are virtually no other population data to address this question for any of these tropical mammals. Alternatively, the species may have been vagile with new individuals moving in quickly to replace residents as they were removed. However, the possibility that younger, smaller animals were moving into territories vacated by larger, resident adults was rejected. Finally, the Leslie model assumes constant probabilities of capture, an assumption that is violated frequently in capture-recapture studies (Blair, 1992) and probably in our study as well. Heterogeneity of capture probabilities dictates that sampling be carried out over an appreciable period of time.

At Cuzco Amazónico sampling for only a few days would have provided an inadequate sample of species composition along any one set of trails, but perhaps 12 days were unnecessary. In considering the site as a whole, more than $90 \%$ of all species trapped in a given season were captured within the first 7 days. We see this pattern more clearly by examining days on which specific species were captured (Tables 1-4). Discounting larger taxa represented only by juveniles, six species were scarce (captures $\leqslant 5$ ) in the dry season (Marmosops parvidens, Neacomys spinosus, Oecomys superans, Oecomys tapajinus, Oryzomys yunganus and Rhipidomys sp.), and six were scarce in the wet season (Marmosops parvidens, Marmosa murina, Neacomys spinosus, Neacomys tenuipes, Oecomys tapajinus and Oryzomys yunganus). Yet in each season, the majority of species captured in that season were taken within the first 5 days of trapping. Most of the scarce species proved easy to capture. Only Rhipidomys sp. was not taken in the first 5 days of trapping in the dry season. However, Rhipidomys was taken within the first 5 days in the wet season, when it was also more abundant. In the wet season, only Neacomys tenuipes was not captured during the first 7 days. Rhipidomys sp. may be difficult to capture during certain parts of the year, and $\mathcal{N}$. tenuipes is scarce and difficult to capture throughout the year. With the exception of these two taxa, 7 days of trapping along each trapline was sufficient to sample both rare and abundant species present. A caveat to this is that our study considered only those species that we captured at the site. Additional rare species may occur here, but it is impossible to calculate how long it would take to capture animals whose identities, and thus whose habits, are unknown.

Seven days was also sufficient to estimate community structure, i.e. the relative abundances of the species present, in some cases. Our comparison of community structures based on the first 7 days of trapping versus the last 5 days of trapping was of questionable reliability because of the small sample sizes. The second trapping period provided few new species, but the relative frequencies of species was different in two of the four data sets. For determination 
of both the species present and community structure, 7 days should be considered the minimum trapping period.

If our results are representative, community structure of abundant small mammal species remains stable through the dry and rainy seasons. At Cuzco Amazónico, abundant species were evenly distributed throughout the site. However, rare species were heterogeneous in their distribution, both in time and space. These findings have important implications both for studies of mammalian communities in lowland tropical rain forests and for conservation of those communities. Surveys of small mammals are best conducted during both the rainy and dry seasons, but if it is possible to visit a site only once, it would be better to carry out field work in the wet season when small mammals are more abundant (or easier to capture) and more scarce species are likely to be taken. It is inevitable that some rare species will be missed by sampling in only one season. To most efficiently sample a site, multiple traplines should be run both at and above ground level in each habitat type for a period of at least 7 days each. Focusing on community structure based solely on the most abundant small mammals might lead one to conclude that conservation efforts need not consider preservation of all habitats. Based on rarer species, however, there appears to be heterogeneity of habitat on a finer scale that is easy to miss or ignore.

\section{ACKNOWLEDGEMENTS}

We thank Rosa Arana C., Terry Doonan, Errol D. Hooper, Cecilia Pacheco A., and Victor Pacheco for their assistance in the field. Alwyn H. Gentry aided our understanding of the vegetational associations in which we worked. José Purisaca P., Dirección General Forestal y de Fauna, Ministerio de Agricultura, Lima, granted permits for our field work. José E. Koechlin, of Cuzco Amazónico Lodge, provided excellent facilities and support for our studies there. Anthony B. Luscombe and the Asociación de Ecología y Conservación (ECCO) were instrumental in assisting with logistics, equipment and supplies in Peru and contributed immeasurably to the success of our work. William E. Duellman and Philip S. Humphrey's efforts in securing funds and aiding in logistics are most appreciated. William E. Duellman, Philip S. Humphrey, Duke S. Rogers, and an anonymous reviewer provided constructive suggestions that significantly enhanced our manuscript. We are grateful to Amy Lathrop for Figure 1 and to Linda Trueb for Figure 2. Field work at Cuzco Amazónico was supported by National Geographic Society Grant 4016-89 and the University of Kansas Museum of Natural History. Portions of this project were funded by the $\mathrm{E}$. Raymond and Mary Hall Fund and the Glen C. Rinker Memorial Fund of the University of Kansas Museum of Natural History.

\section{REFERENCES}

Blair SM. 1992. Assessing small mammal abundance using capture-mark-recapture data: performance of three commonly used estimators, CAPTURE, JOLLY, and the Minimum Number Known Alive. Unpublished M.S. Thesis, The University of Kansas.

Ghesser RT, Hackett SJ. 1992. Mammalian diversity in South America. Science 255: 15021504.

Ghesson PL, Case TJ. 1986. Overview: nonequilibrium community theories: chance, variability, history, 
and coexistence. In: Diamond JL, Case TJ, eds. Community ecolog?. New York: Harper and Row, 229239.

Davis TJ, Fox C, Salinas L, Ballón G, Arana C. 1991. Annotated checklist of the birds of Cuzco Amazónico, Peru. Occasional Papers of the Museum of Natural Histon, The University of Kansas 144: 119.

Duellman WE, Koechlin JE. 1991. The Reserva Cuzco Amazónico, Peru: Biological investigations, conservation, and ecotourism. Occasional Papers of the Museum of Natural History. The University of Kansas 142: 138.

Duellman WE, Salas AW. 1991. Annotated checklist of the amphibians and reptiles of Cuzco Amazónico, Peru. Occasional Papers of the Museum of Natural History. The Liniversity of Kansas 143: 1-13.

Emmons LH. 1982. Ecology of Proechimys (Rodentia, Echimyidac) in south-eastern Peru. Tropical Ecology 23: 280290.

Emmons LH. 1984. Geographic variation in densities and diversities of non-flying mammals in Amazonia. Biotropica 16: 210-222.

Emmons LH. 1987. Comparative feeding ecology of felids in a ncotropical rainforest. Behanioral Ecology and Sociabiology 20: $271-283$.

Emmons LH. 1991. Mammals of Alto Madidi. Rapid Assessment Working Papers 1: 23-25, 72-73.

Fonseca GAB, Kierulff MCM. 1989. Biology and natural history of Brazilian Atlantic forest small mammals. Bulletin of the Florida State Museum, Biological Sciences 34: 99152.

Gentry AH (ed.). 1990. Four. Neotropical rainforests. New Haven: Yale University Press, 627 pp.

Handley CO Jr. 1976. Mammals of the Smithsonian Venezuelan Project. Brigham Voung University Science Bulletin 20(5): 1-89.

Hayne DW. 1949. Two mothods for estimating population from trapping records. Foumal of Mammalogy 30: $399-411$

Janson CH, Emmons LH. 1990. Ecological structure of the nonflying mammal community at Cocha Cashu Biological Station, Manu National Park, Peru. In: Gentry AH, ed. Four Neotropical rainforests. New Havcn: Yale University Press, 314-338.

Malcolm JR. 1990. Estimation of mammalian densities in continuous forest north of Manaus. In: Gentry AH, ed. Four Neotropical rainforests. New Haven: Yale University Press, 339-357.

Mares MA. 1982. The scope of South American biology: perspectives on a decade of research. In: Mares MA, Genoways HH, eds. Mammalian biology in South Imerica. Pymatuning Laboratory of Ecology Special Publication No. 6. Pittsburgh: University of Pittsburgh, 1-26.

Mares MA. 1986. Conservation in South Amcrica: problems, consequences and solutions. Science 233: 734739.

Mares MA. 1992a. Neotropical mammals and the myth of Amazonian biodiversity. Science 255: 976-979.

Mares MA. 1992h. Mammalian diversity in South America. Science 255: 1504-1505.

May RM. 1988. How many species are therc? Science 241: $14+11449$.

Myers N. 1988. Tropical forests and their species: going, going...? In: Wilson EO, ed. Biodizersitz. Washington, DC: National Academy Press, 28-35.

Overton WS. 1971. Estimating the numbers of animals in wildlife populations. In: Giles RH Jr, ed. Irildlife managment tecliniques, 3rd ed. Washington, DC: The Wildlife Society, 403-455.

Patterson BD. 1986. Species loss. Science 234: 1311.

Pimm SL, Gittleman JL. 1992. Biological diversity: where is it? Science 255: 940.

Pine RH. 1982. Current status of South American mammalogy. In: Mares MA, Genoways HH, eds. Mammalian biology' in South America. Pymatuning Laboratory of Ecology Special Publication No. 6. Pittsburgh: University of Pittsburgh, 27-37.

Raven PH. 1988. Our diminishing tropical forests. In: Wilson EO, ed. Biodiversitr. Washington, DC: National Academy Press, 119-122.

Swihart RK, Slade NA. 1990. Long-term dynamics of an early' successional small mammal community. Imerican Midland Naturalist 123: 372-382.

Stallings JR. 1989. Small mammal inventories in an eastern Brazilian park. Bulletin of the Florida State Museum, Biological Sciences 34: 153-200.

Terborgh JW, Fitzpatrick JW, Emmons L. 1984. Annotated checklist of bird and mammal species of Cocha Cashu Biological Station, Manu National Park, Peru. Fieldiana: Zonlogy (New Series) 21: 1-29.

Timm RM, Wilson DE, Clauson BL, LaVal RK, Vaughan CS. 1989. Mammals of the La SelvaBraulio Carrillo complcx, Costa Rica. North Anerican Fauna 75: 1162.

Tosi JA Jr. 1960. Zonas de vida natural en el Perú. Instituto Interanericano de Ciencias Agricolas de la O.E.A., Boletín Técruico 5: 1-271.

White GC, Anderson DR, Burnham KP, Otis DL. 1982. Capture-recapture and removal methods for sampling closed populations. Los Alamos, New Mexico: I.os Alamos National Laboratory, $23.5 \mathrm{pp}$.

Wilson EO (ed.). 1988. Biodiversity. Washington, DC: National Academy Press, 521 pp.

Wilson EO. 1992. The diversity of life. Cambridge, Massachusetts: The Belknap Press, $424 \mathrm{pp}$.

Woodman N, Timm RM, Arana-C R, Pacbeco V, Schmidt GA, Hooper ED, Pacheco-A C. 1991. Annotated checklist of the mammals of Cuzco Amazonico, Peru. Occasional Papers of the Museum of . Natural History, The Lniversity of Kansas 145: 1-12. 